\title{
Knowledge and Attitude of Diabetic Patients towards the Oral Complications of Diabetes Mellitus and Factors Associated with Their Knowledge in Khartoum State, Sudan
}

\author{
Muram Hatim Abdelfatah Elsayed ${ }^{1}$ and Elhadi Mohieldin Awooda ${ }^{1^{*}}$ \\ ${ }^{1}$ Department of Restorative Dentistry, Faculty of Dentistry, University of Medical Sciences and \\ Technology, Sudan.
}

Authors' contributions

This work was carried out in collaboration between both authors. Author MHAE designed the study, managed the literature searches, collected data, performed the statistical analysis and wrote the first draft of the manuscript. Author EMA wrote the protocol, designed the study and revised the manuscript. Both authors read and approved the final manuscript.

Article Information

DOI: $10.9734 / B J M M R / 2017 / 32035$

Editor(s):

(1) Ibrahim El-Sayed M. El-Hakim, Ain Shams University, Egypt and Riyadh College of Dentistry and Pharmacy, Riyadh,

Saudi Arabia.

Reviewers:

(1) Takahiro Kanno, Shimane University, Japan. (2) Karpal Singh Sohal, Muhimbili University of Health and Allied Sciences, Tanzania. (3) Mehmet Fatih Şentürk, Suleyman Demirel University, Isparta, Turkey. (4) V. Harshini, Employment State Insurance Corporation Medical College Post graduate Institute and Research, Bangalore, India

Complete Peer review History: http://www.sciencedomain.org/review-history/18986

Original Research Article

Received $29^{\text {th }}$ October 2016

Accepted $2^{\text {nd }}$ February 2017

Published $9^{\text {th }}$ May 2017

\section{ABSTRACT}

Background: Diabetes Mellitus is a chronic long term condition, affecting all age groups. Uncontrolled diabetes can lead to serious oral complications ranging from acute to chronic, which manifest in several ways and can affect diabetic patient's overall health.

Aim: The aim of this study was to evaluate knowledge and attitude of diabetic patients towards the oral complications of diabetes.

Materials and Methods: A descriptive cross-sectional hospital-based study, among 6 different hospitals in Khartoum State, Sudan. The study duration was from $1^{\text {st }}$ December $2015-31^{\text {st }}$ January 2016. A total number of 164 diabetic patients participated in the study, they were 
interviewed using structured closed ended questionnaire. It consisted of different parts assessing diabetic patients' socio-demographic characteristics, knowledge and attitude towards diabetes mellitus oral complications, factors that could be associated with their knowledge, as well as their source of information. Comparison between variables by Chi-squire test with the level of significance set at $P<0.05$.

Results: The average correct response to the knowledge questions was only $47.5 \%$. A Few participants agreed with the statement that "diabetes increases the risk of fungal infection" and majority were denying the fact about the increased risk for dental caries. Participants' Knowledge on the oral complications of diabetes mellitus was found to be associated with their ages $(P=$ $.000)$, levels of education $(P=.002)$, duration of residence in Khartoum state $(P=.018)$ and duration since they have been diagnosed with the disease $(P=.007)$, but there was no significant difference in knowledge concerning gender differences $(P=.06)$.

Conclusion: participants' knowledge regarding Diabetes mellitus oral complications was found to be limited. It was associated with their ages, levels of education, times since they have been diagnosed and durations of residence in Khartoum state. Efforts should be taken to improve diabetic patients' knowledge regarding diabetes oral complications.

Keywords: Diabetes mellitus; diabetes oral complications; diabetes mellitus and fungal infection; Sudan.

\section{INTRODUCTION}

Diabetes Mellitus is a chronic metabolic disorder which affects all age groups with no sex predilection. It is characterized by relative or absolute insufficiency of insulin that leads to carbohydrate's metabolism disturbances marked by persistent glycemias [1]. Diabetes Mellitus (DM); prevalence and incidence are increasing steadily worldwide, at such rate that the WHO has declared the disease as an epidemic [2], while its prevalence in Sudan according to the available data on 2015 was $7.7 \%$ [3].

Uncontrolled diabetes can lead to serious complications ranging from acute to chronic, affecting almost all tissues in the body; including the cardiovascular system, the nervous system, eyes, kidneys and many other parts of the body [4]. One of these is the oral consequences which manifest in several ways like xerostomia, dental caries, fungal infections, periodontal diseases that can end with teeth loss and impaired gingival health and many more other complications [5]. Periodontal diseases have been considered to be the sixth most prevalent complication of diabetes mellitus following the other systemic complications [6]. These oral complications can affect the individual's diet and overall health since the oral cavity is the first part of the digestive system and those oral complications can worsen the glycaemic status of the diabetic patients.

It has been reported that the prevalence and severity of periodontal diseases in diabetic patients are up to three times more than in general population [7]. In addition, many studies proved that compromised periodontal tissues could worsen glycaemia control for diabetic patients as well [8]. The theory behind that is not fully understood but many factors have been proposed such as increased collagenase activity, a decrease in collagen synthesis, advanced glycation end products and altered immune response [9]. Unfortunately, the existence of a two-way relationship between diabetes mellitus and oral cavity diseases is not well recognized by the community [10]. Diabetic patients must be knowledgeable about diabetes oral complications; so they can implement this knowledge to obtain good oral health using proper ways and tools. This is crucial for control of diabetes mellitus and overall health.

In Sudan, no published study reflected this aspect of knowledge which indicates the need for research to clarify the level of awareness of diabetes oral complications among the diabetic patients. So this study was aimed to evaluate knowledge and attitude of Sudanese diabetic patients towards diabetes mellitus oral complications.

\section{MATERIALS AND METHODS}

A descriptive cross-sectional hospitals-based study was conducted among Sudanese diabetic patients, who were receiving care at six different diabetic clinics located in Khartoum state-Sudan represented in (Khartoum, Khartoum North and Omdurman cities) during the period from $1^{\text {st }}$ December $2015-31^{\text {st }}$ January 2016. 
A total of 164 diabetic patients (type 1and type 2) of all age groups participated in the study; they were given the option of voluntary participation and they signed informed written consents. Ethical approval was obtained from the National Health Research Ethics Committee in Khartoum state Ministry of Health and permissions' from each hospital administrations. Those with gestational diabetes, mental issues, severely ill or not willing to be interviewed were excluded.

The Sample size was determined by the following formula based on Sudanese prevalence of diabetes mellitus $(7.7 \%)$ in 2015 , estimated by Sudanese Diabetic Association (SDA) as part of International Diabetic Federation (IDF) [3].

$$
\begin{aligned}
& \frac{n=P \times Q \times z 2}{\mathrm{~d}^{2}} \\
& \mathrm{n}=\text { sample size } \\
& \mathrm{P}=\text { prevalence rate of } \mathrm{DM} \\
& \mathrm{Q}=\text { non prevalence rate i.e. }(1-\mathrm{P}) \\
& \mathrm{Z}=\text { standard normal value for } 95 \% \\
& \quad \text { confidence level }(\mathrm{Z}=1.96) \\
& \mathrm{d}=\text { margin of desired error taken as } 5 \% .
\end{aligned}
$$

Participants were interviewed using structured close ended questionnaire used in a previous study of relative aims [11] and consisting of different parts assessing the socio-demographic characteristics of the diabetic patients. Knowledge and attitude of the patients regarding diabetes oral complications as well as their source of information have been assessed. It also assesses the relation between participants' knowledge and their age, level of education, the time since they have been diagnosed with DM, and finally the duration of residence in Khartoum state. The questionnaire has been modified to fit with the study and translated to Arabic by expert in both Arabic and English.

A pilot study was carried out among twelve participants to assess the questionnaire's reliability and it was adjusted accordingly. Likert scale for knowledge assessment was used in the questionnaire to address diabetic patients' knowledge on diabetes oral complications, given five various responses formats (Agree, strongly agree, disagree, strongly disagree, neither agree nor disagree). Participants' responses to given correct knowledge sentences were rated on according to this five points Likert scale on basis of 1 = strongly disagree, 2 = disagree, $3=$ neither agree nor disagree (Don't know), $4=$ agree and $5=$ strongly agree. The higher score the better the knowledge. After analysis of the scale, patients who responded more with strongly disagree and disagree responses together were considered to be less knowledgeable than those who responded with agree and strongly agree on responses. Correct knowledge sentence were given as follow: Uncontrolled Diabetes Mellitus affects the oral cavity health; Uncontrolled Diabetes Mellitus increases the risk for dental caries, uncontrolled Diabetes Mellitus increases the risk for fungal infection, uncontrolled Diabetes Mellitus affect gum health and can end with teeth loss, gum Diseases worsen glycamic status of diabetic patients and make it difficult to control [12].

The data obtained processed and analyzed using statistical package for social sciences program (SPSS) version 17 (SPSS Inc., Chicago, IL, USA). Descriptive statistics were used to report the results. Comparisons between variables were done using Chi-square test with the level of significance set at $(P<0.05)$.

\section{RESULTS}

Among the 164 diabetic patients interviewed, the female gender predominated $(60.4 \%)$ and the highest percentage of the respondents (35.37\%) was in the age group between 40 and 59 years old. With regard to participants' diabetes profile, most of them (46.3\%) didn't know which type of diabetes they had and $34.8 \%$ had been diagnosed with diabetes for $1-5$ years. The majority of the participants $(34.1 \%)$ were of college educational levels or above and had been living in Khartoum state for more than 10 years $(77.6 \%)$, as shown in Table 1.

\subsection{Diabetes Oral Complications Related Knowledge}

The survey indicated that the average correct response to knowledge questions among the participants was $47 \%$. Of the diabetic patients assessed, only $39.7 \%$ knew that DM increases the risk for dental caries, and $42.7 \%$ were aware of the increased risk for fungal infections.

However, as for Knowledge on the two-ways relationship between DM and periodontal infections, only $57.9 \%$ of the participants were aware that DM increases the risk for periodontal diseases and just $58.6 \%$ knew that periodontal infections worsen glycaemia status as well and make it more difficult to control, as shown in Fig. 1. Regarding signs of gum diseases, $67.7 \%$ 
knew that bleeding during brushing is a sign of gum diseases.

Table 1. Distribution of the study population according to their socio-demographic characteristics

\begin{tabular}{|c|c|c|}
\hline $\begin{array}{l}\text { Socio-demographic } \\
\text { characteristic of the participants }\end{array}$ & $\mathbf{N}$ & $\%$ \\
\hline \multicolumn{3}{|l|}{ Gender } \\
\hline Male & 65 & $39.6 \%$ \\
\hline \multicolumn{3}{|l|}{ Age (years) } \\
\hline$<20$ & 49 & $29.9 \%$ \\
\hline $20-39$ & 19 & $11.6 \%$ \\
\hline $40-59$ & 58 & $35.4 \%$ \\
\hline 60 and above & 38 & $23.2 \%$ \\
\hline \multicolumn{3}{|l|}{ Educational level } \\
\hline No formal education & 11 & $6.7 \%$ \\
\hline Primary & 51 & $31.8 \%$ \\
\hline Secondary & 46 & $28 \%$ \\
\hline College and above & 56 & $34.1 \%$ \\
\hline \multicolumn{3}{|l|}{ Type of diabetes } \\
\hline Type 1 & 37 & $22.6 \%$ \\
\hline Type 2 & 51 & $31.1 \%$ \\
\hline Don't know which type & 76 & $46.3 \%$ \\
\hline \multicolumn{3}{|l|}{$\begin{array}{l}\text { Duration of residence in } \\
\text { Khartoum State (years) }\end{array}$} \\
\hline$<5$ & 12 & $9.0 \%$ \\
\hline $5-10$ & 18 & $13.4 \%$ \\
\hline$>10$ & 104 & $77.6 \%$ \\
\hline \multicolumn{3}{|l|}{$\begin{array}{l}\text { Duration since diagnosis with } \\
\text { diabetes (years) }\end{array}$} \\
\hline$>1$ & 20 & $12.2 \%$ \\
\hline $1-5$ & 57 & $34.8 \%$ \\
\hline $6-10$ & 37 & $22.6 \%$ \\
\hline More than 10 & 50 & $30.5 \%$ \\
\hline
\end{tabular}

\subsection{Complications}

Knowledge on DM oral complications was found to be the least (48\%) compared to other systemic complications; heart (69\%), kidney (78.70\%), eyes $(89 \%)$, nerves $(76 \%)$, and feet $(75 \%)$. The difference seen between the gender as far as knowledge on complications of diabetes was not statistically significant $(P=0.06)$, as shown in Table 2.

The difference in knowledge on DM oral complications across age groups was statistically significant $(P=.000)$, as shown in Table 3 . Those younger in age (less than 20 years old) were found to be the most unaware of DM oral complications (frequent "disagree and strongly disagree" responses to correct knowledge sentences). Those between 40-59 years old were found to be the most familiar with DM oral complications (frequent "agree and strongly agree" responses to correct knowledge sentences).

The Difference between participants' levels of education was found to be significantly affecting their knowledge $(P=.002)$. Those with no formal education were found to be the least aware of diabetic oral complications (lack of "strongly agree" response to correct knowledge sentences), while those with educational levels of college and above were the most informed, as shown in Fig. 2.

Table 2. Comparison of participant's knowledge regarding diabetes mellitus oral complications according to their gender (Responses to correct knowledge sentences)

\begin{tabular}{lllllll}
\hline Gender & \multicolumn{5}{c}{ Response } & $P=.06$ \\
\cline { 2 - 6 } & $\begin{array}{l}\text { Strongly } \\
\text { disagree }\end{array}$ & Disagree & Neutral & Agree & $\begin{array}{l}\text { Strongly } \\
\text { agree }\end{array}$ & Total \\
\hline Male & $7(4.3 \%)$ & $14(8.5 \%)$ & $9(5.5 \%)$ & $24(14.6)$ & $11(6.7 \%)$ & $65(39.6 \%)$ \\
Female & $17(10.4 \%)$ & $26(15.9 \%)$ & $13(7.9 \%)$ & $32(19.5)$ & $11(6.7 \%)$ & $99(60.4 \%)$ \\
Total & $24(14.6 \%)$ & $40(24.4 \%)$ & $22(13.4)$ & $56(34.1)$ & $22(13.4)$ & $164(100 \%)$ \\
\hline
\end{tabular}

Table 3. Comparison of participants' knowledge regarding diabetes mellitus oral complications regarding age differences (Responses to correct knowledge sentences)

\begin{tabular}{lllllll}
\hline $\begin{array}{l}\text { Participants' } \\
\text { ages (years) }\end{array}$ & $\begin{array}{l}\text { Strongly } \\
\text { disagree }\end{array}$ & Disagree & $\begin{array}{l}\text { Neither } \\
\text { agree nor } \\
\text { disagree }\end{array}$ & Agree & $\begin{array}{l}\text { Strongly } \\
\text { agree }\end{array}$ & Total \\
\hline Less than 20 & $20(12.2 \%)$ & $16(9.8 \%)$ & $4(2.4 \%)$ & $6(3.7 \%)$ & $3(1.8 \%)$ & $49(29.9 \%)$ \\
$20-39$ & $0(.0 \%)$ & $5(3.0 \%)$ & $1(0.6 \%)$ & $10(6.1 \%)$ & $3(1.8 \%)$ & $19(11.6 \%)$ \\
$40-59$ & $2(1.2 \%)$ & $9(5.5 \%)$ & $11(6.7 \%)$ & $25(15.2 \%)$ & $11(6.7 \%)$ & $58(35.4 \%)$ \\
60 and above & $2(1.2 \%)$ & $10(6.1 \%)$ & $6(3.7 \%)$ & $15(9.1 \%)$ & $5(3.0 \%)$ & $38(23.2 \%)$ \\
Total & $24(14.6 \%)$ & $40(24.4 \%)$ & $22(13.4 \%)$ & $56(34.1 \%)$ & $22(13.4)$ & $164(100 \%)$ \\
\hline
\end{tabular}




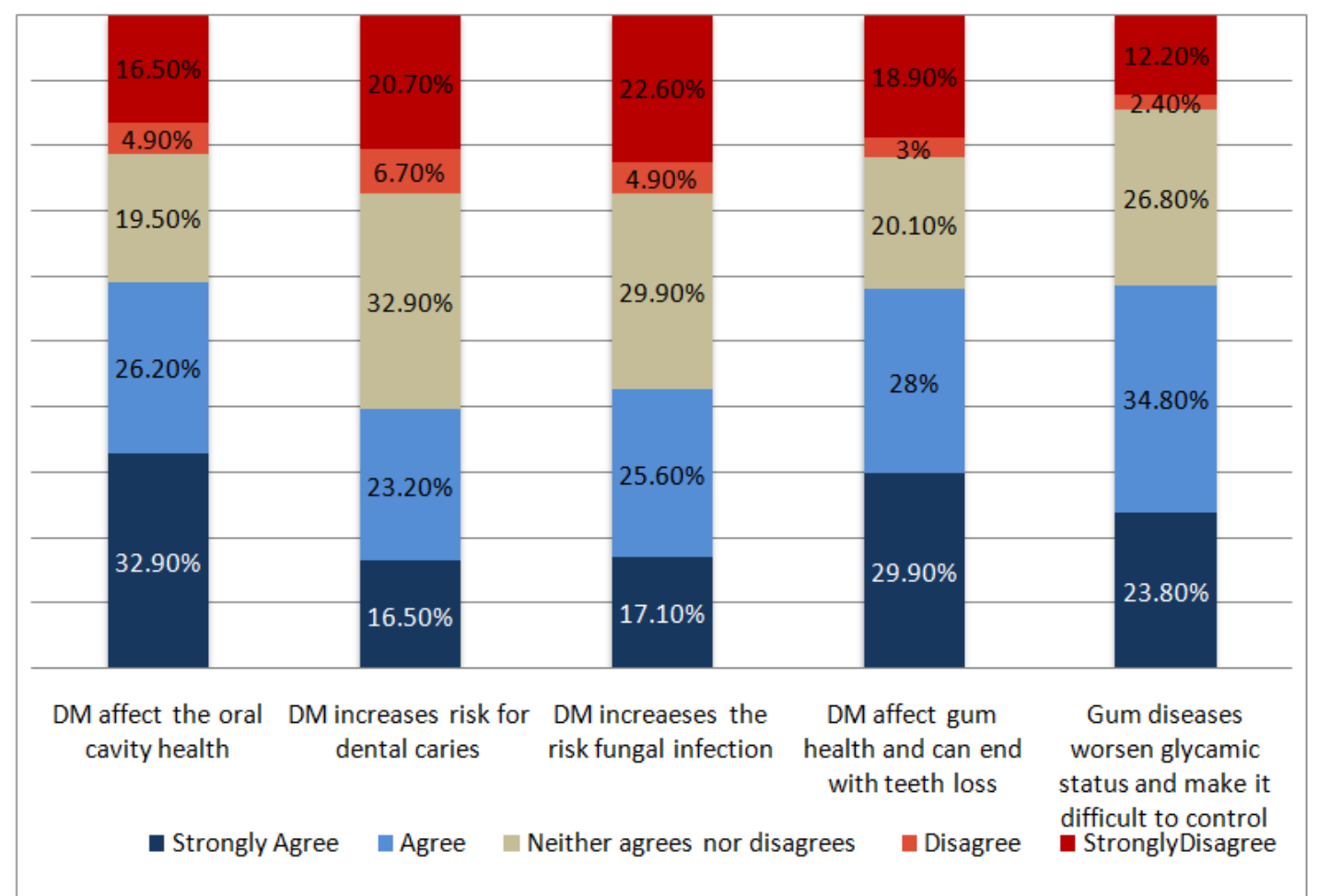

Fig. 1. Diabetic patients' responses to knowledge sentences regarding diabetes oral complications

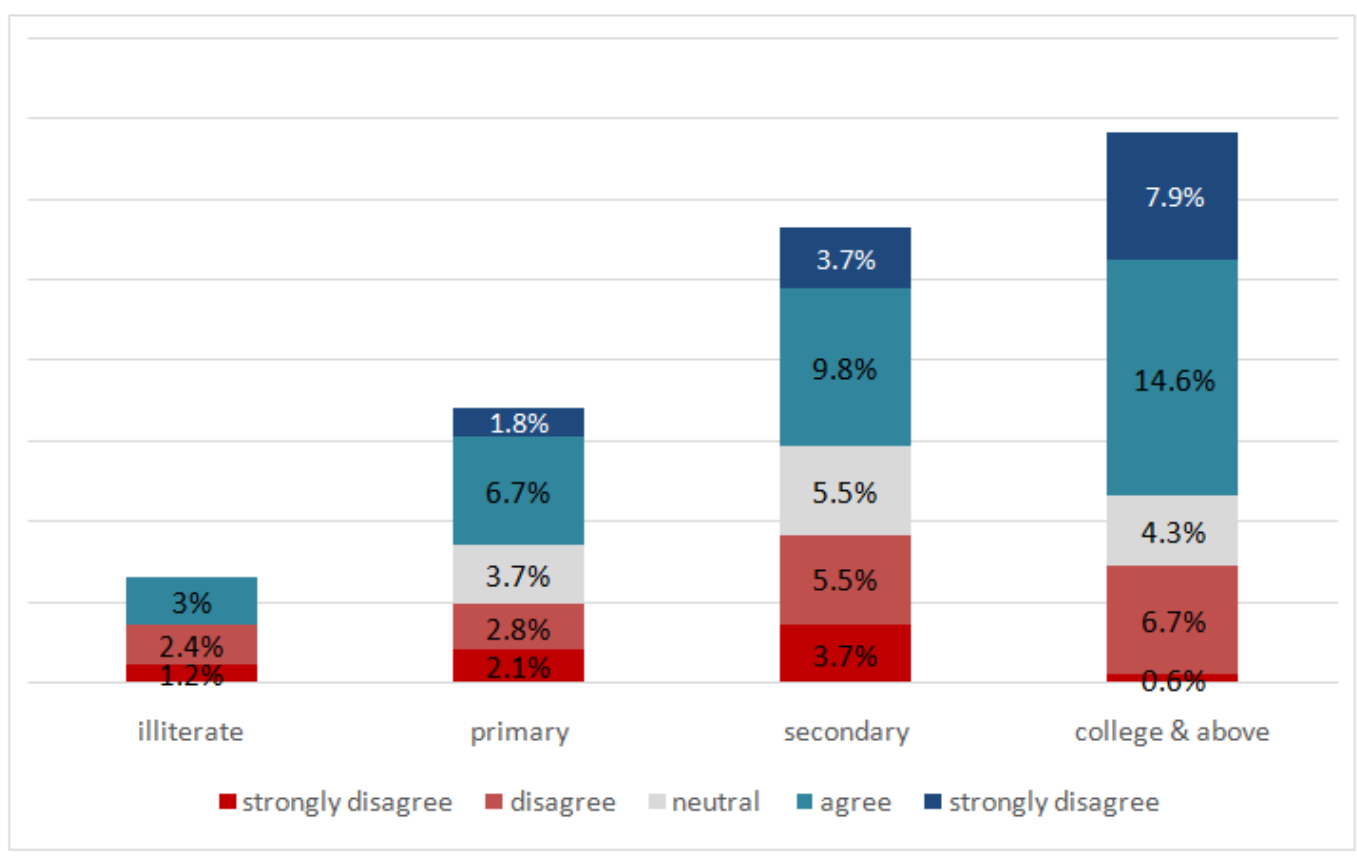

Fig. 2. Comparison of participant's knowledge regarding diabetes oral complications according to their levels of education (Responses to correct knowledge sentences) 
The results show a significant difference in knowledge between people who lived for different periods of time in the Khartoum state $(P=.01)$, as explained in Table 4. Those stayed for more than 10 years responded more correctly than who those lived for less than 5 years in Khartoum state.

A level of significance $(P=.007)$ indicates an association between Participants' knowledge and period of times since they have been diagnosed with DM. Those with a longer duration of diabetes were found to be more informed of diabetes oral complications (frequent "agree and strongly agree" responses to correct knowledge sentences) than those diagnosed with DM for less than 1 year, as shown in Fig. 3.
Concerning tooth brushing frequency, $1.8 \%$ of the contributors did not use a brush on a daily basis and $29.9 \%$ brushed their teeth once a day. A significantly higher number of the participants $(52.4 \%)$ brushed twice a day and only $16.5 \%$ brush their teeth more than twice a day.

Only One-quarter of the participants (25\%) visits the dentist on a regular basis, and just $51.80 \%$ of the participants visited the dentist during the last year, in comparison to the high frequent regular visits to the physician, as shown in Table 5. For those who visited the dentist during the last year, the main reason behind this was to seek a treatment for a toothache $(47.1 \%)$, as shown in Fig. 4.

Table 4. Comparison of participant's knowledge regarding diabetes oral complications according to their residence duration in Khartoum state (Responses to correct knowledge sentences)

\begin{tabular}{|c|c|c|c|c|c|c|c|}
\hline \multirow[b]{2}{*}{$\begin{array}{l}\text { Participants' } \\
\text { Residence } \\
\text { duration in } \\
\text { Khartoum } \\
\text { state (years) }\end{array}$} & \multicolumn{6}{|c|}{ Responses } & \multirow[t]{2}{*}{$P=.01$} \\
\hline & $\begin{array}{l}\text { Strongly } \\
\text { Disagree }\end{array}$ & Disagree & $\begin{array}{l}\text { Neither } \\
\text { agree nor } \\
\text { disagree }\end{array}$ & Agree & $\begin{array}{l}\text { Strongly } \\
\text { agree }\end{array}$ & Total & \\
\hline Less than 5 & $5(3.7 \%)$ & $3(2.2 \%)$ & $1(0.7 \%)$ & $2(1.5 \%)$ & 1 (0.7\%) & $12(9.0 \%)$ & \\
\hline $5-10$ & $4(3.0 \%)$ & $6(4.5 \%)$ & $1(0.7 \%)$ & 7 (5.2\%) & $0(0.0 \%)$ & $18(13.4 \%)$ & \\
\hline More than 10 & $8(6.0 \%)$ & $23(17.2 \%)$ & $17(12.7 \%)$ & $38(28.4 \%)$ & $18(13.4 \%)$ & $104(77.6 \%)$ & \\
\hline Total & $17(12.7 \%)$ & $32(23.9 \%)$ & $19(14.2 \%)$ & $47(35.1 \%)$ & $19(14.2 \%)$ & $134(100.0 \%)$ & \\
\hline
\end{tabular}

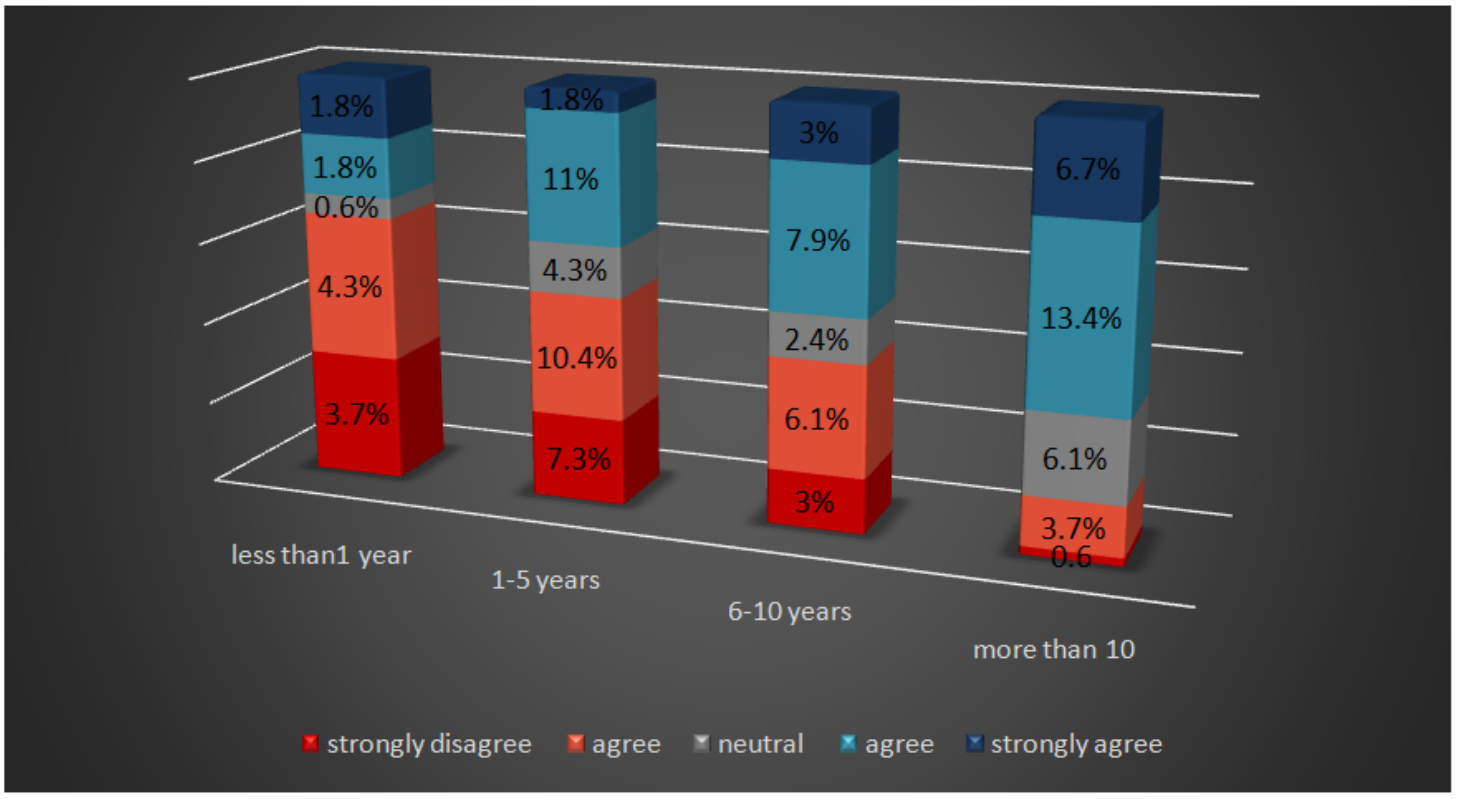

Fig. 3. Comparison of participant's knowledge regarding diabetes mellitus oral complications according to time since they have been diagnosed with the disease (Responses to correct knowledge sentences) 
Table 4. Frequency of participants' visits to the dentist compared to the physician

\begin{tabular}{|l|r|}
\hline Attending Regular check-ups to the Dentist & $25.00 \%$ \\
\hline Attending Regular check-ups to the physician & $77.40 \%$ \\
\hline Visited the dentist during the last year & $51.80 \%$ \\
\hline Visited the physician during the last year & $87.20 \%$ \\
\hline
\end{tabular}

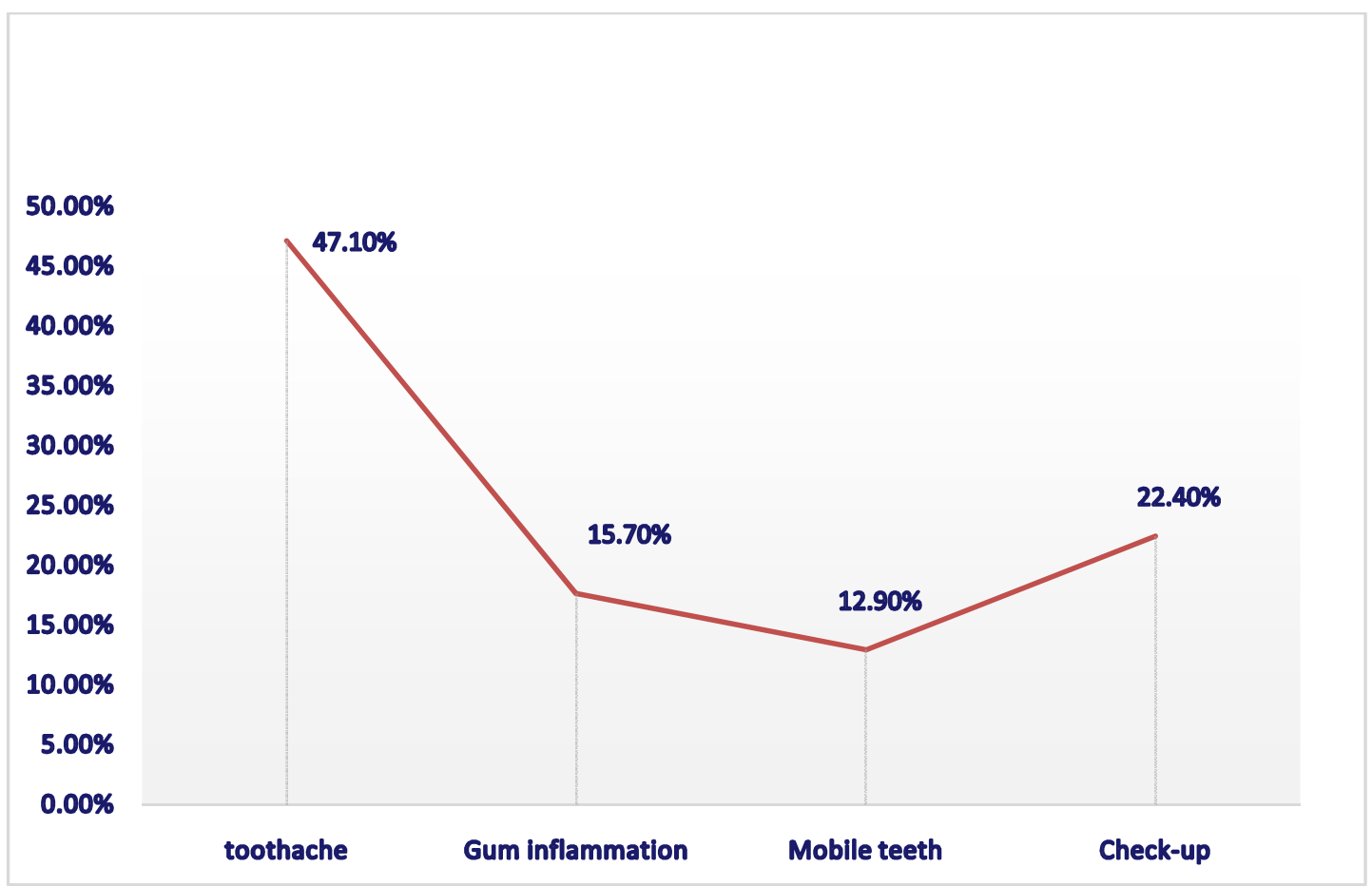

Fig. 4. Reasons behind participants' visits to the dentist during the last year

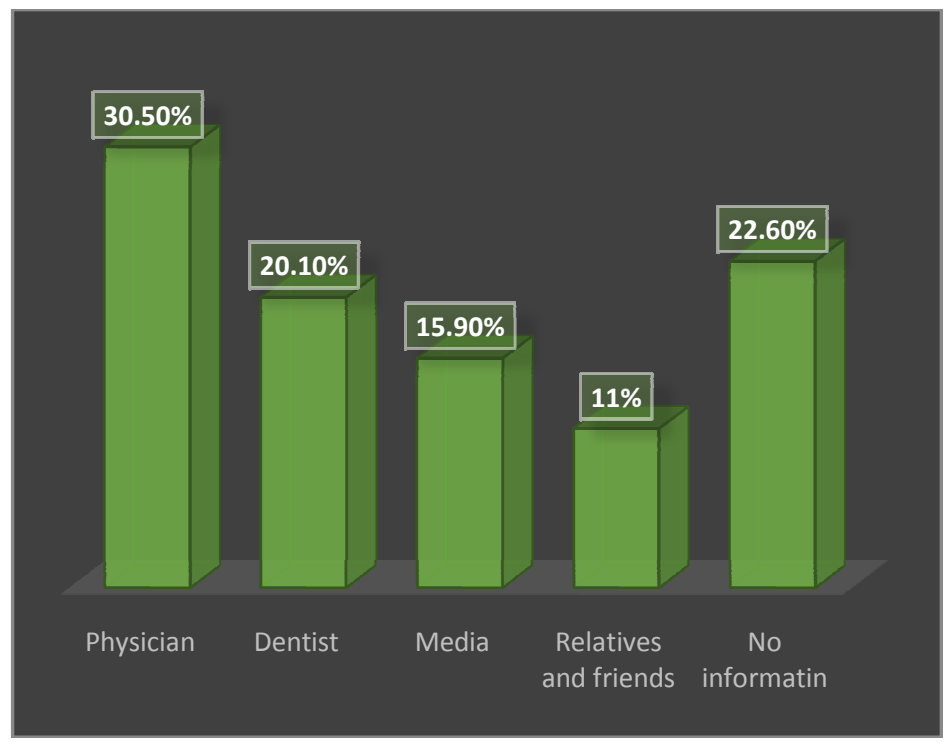

Fig. 5. Sources of diabetic patients' information about diabetes oral complications 
As the participants were asked about their attitude if they encountered an oral problem, results came to show that $10.4 \%$ will ignore it, $12.2 \%$ will go for self-remedy, $11.6 \%$ will consult the physician and the majority $(65.9 \%)$ will refer to the dentist.

Concerning diabetic patients' eagerness and seek for knowledge; $92.1 \%$ of them said they have the desire to receive education on diabetes oral complications. At the same time, $22.6 \%$ of the patients stated that they have no information regarding diabetes oral complications. Physicians were found to be the main source of the knowledge, as shown in Fig. 5.

\section{DISCUSSION}

Diabetic patient's knowledge and attitude towords their increased risk for oral diseases in Khartoum state is not well studied so far. There is no previous study, or at least, unpublished data regarding this issue.

The results showed that the average correct response to the questions was only $47.5 \%$. Diabetic patients must be knowledgeable about diabetes oral complication. A Few participants agreed with the statement that "diabetes increases the risk for fungal infection". The majority were denying the fact that diabetes increases the risk of dental caries, which seems likely to be the most unfamiliar oral complication of diabetes. This fact matches a similar study in Libya [10]. Knowledge of the two-way relationship between $\mathrm{DM}$ and periodontal infections was also limited. Only half of the participants were aware that DM could affect the gum health as well as the periodontal infections worsen glycaemia status, making it more difficult to control. Similar discoveries of inadequate knowledge of diabetic patients were found also in Jordan [13], New York [14], and Saudi Arabia $[15,16]$. Efforts should be taken to raise diabetic patients' awareness about diabetes oral complications and media should be used judiciously in the awareness process, for example, T.V, posters in the streets and so on.

The difference seen between the genders as far as knowledge on oral complications of diabetes was not statistically significant. Unlike a similar study in India showed that women were more likely to test oral health measures than men [17].

More attention should be directed towards those who are recently diagnosed with DM and the ones who are younger in age. It was found that they are the most unaware about diabetes oral complications; this could be connected to the fact that with the long-term exposure to health care providers, diabetic patients become more aware of their conditions, also their knowledge on diabetes oral complications will increase. As physicians were found to be the main source of the participants' knowledge in this study, more attention should be directed to include media (suitable and simple informative materials), educational programs, and therapeutic days in schools calendars and health programs in the awareness campaign. This should be arranged by all of the health care providers, Ministry of Health and government members together in order to increase the community knowledge about this disease and its oral complications.

The longer duration of residence inside Khartoum state, the better the knowledge. This could be explained by the relative availability of facilities starting from educations to medical services.

Regarding participants' practices, the survey revealed that they weren't to the desired levels. Nearly half of the participants did not brush their teeth twice on daily basis. This low percentage matches the findings of a relative study in Libya were only a few number of the respondents used a toothbrush on the twice daily basis [10]. The percentage of participants who brushed their teeth once a day was (29.9\%), which is lower than those reported by Karikoski et al. [18] (83\%) and Murtomaa et al. [19] (91\%). Diabetic patients should be informed that through preventive oral health measures, diabetes oral complications could be minimized or avoided and diabetes control would be easier.

In this study, a few of the participants visited the dentist during the last year and mainly for treatment of a toothache. Also, a minority were on regular dental check-ups, in comparison with the frequent regular visits to the physician. This clearly shows that oral health is not a major priority for this particular group of diabetic patients compared to systemic side effects concerns. This matches another study finding conducted in Jordan, were only $10 \%$ of the diabetic patients attended dental appointments regularly [13]. Diabetic patients need to be better informed about their increased risk for periodontal disease and that oral and dental health improves their quality of lives since it plays an important role in nutrition and control of level of glucose in blood. 
One of the potential causes of patients' lack of knowledge is believed to be the lack of information provided by the health care providers. Concerning this matter, a few of the participants stated that they had received advice from their physicians or dentists regarding DM oral complications. This indicated a huge underestimation from physicians and dentists to the importance of knowledge about oral complications for diabetic patients in Khartoum state. In comparison with the finding of another survey that was done by Allen et al, which revealed that dentists were the most common source of information about diabetes oral complications [20]. So, dentists, physicians, and other healthcare providers should give out more efforts to increase diabetic patients' knowledge of DM oral complications.

\section{CONCLUSION}

Diabetic patients' knowledge regarding Diabetes mellitus oral complications was found to be limited. It was found to be associated with their ages, levels of education, times since they have been diagnosed with diabetes and duration of residence in Khartoum state. Efforts should be taken to improve diabetic patients' knowledge and attitude regarding DM oral complications.

\section{ACKNOWLEDGEMENTS}

Great appreciation and thanks to everyone who helped and supported in this research and many thanks to Alya Eltayeb for the statistical assistance.

\section{CONSENT}

As per international standard or university standard, patient's written consent has been collected and preserved by the authors.

\section{ETHICAL APPROVAL}

As per international standard or university standard, written approval of Ethics committee has been collected and preserved by the authors.

\section{COMPETING INTERESTS}

Authors have declared that no competing interests exist.

\section{REFERENCES}

1. King $H$, Ronald $E$, William H. Global burden of diabetes. Diabetes Care. 1998;21(9):1414-1431.

2. Wild S, Roglic G, Green A, Sicree R, King $\mathrm{H}$. Global prevalence of diabetes: Estimates for the year 2000 and projections for 2030. Diabetes Care. 2004;27(5):1047-1053.

3. Beatriz Y, Sheree D, Courtney S, Olivier J, Evariste B, et al. Global diabetes scorecard tracking progress for action. Sudanese Diabetes Association a Member of IDF. 2015;59:71.

Available:http://www.idf.org/membership/m ena/sudan

(Accessed $28^{\text {th }}$ January 2015)

4. Gadsby R. Epidemiology of diabetes. Adv Drug Deliv Rev. 2002;54(9):1165-1172.

5. Eldarrat AH. Diabetic patients: Their knowledge and perception of oral health. Libyan J Med. 2011;6:5691.

DOI: $10.3402 / \mathrm{ljm} . v 6 \mathrm{i} 0.5691$

6. Loe H. Periodontal disease: The sixth complication of diabetes mellitus. Diabetes Care. 1993;16:329-34.

7. Mealey BL, Ocampo GL. Diabetes mellitus and periodontal disease. Periodontal 2000. 2007;44:127-153.

8. Taylor GW, Borgnakke WS. Periodontal disease: Associations with diabetes, glycemic control and complications. Oral Dis. 2008;14:191-203.

9. Ritchie CS. Mechanistic links between type 2 diabetes and periodontitis. J Dent. 2009;37:578-579.

10. Eldarrat $\mathrm{AH}$. Awareness and attitude of diabetic patients about their increased risk for oral diseases. Oral Health Prev Dent. 2011;9(3):235-241.

11. Faten $M$, Neima $A$. Diabetic patients knowledge, attitude and practice toward oral health. Journal of Education and Practice. 2013;4(20):1735-2222.

12. Bowyer $V$, Sutcliffe $P$, Ireland $R$, Lindenmeyer A, Gadsby R, Graveney M, et al. Oral health awareness in adult patients with diabetes: A questionnaire study. $\mathrm{Br}$ Dent J. 2011;23;211(6):E12.

DOI: 10.1038/sj.bdj.2011.769

13. Al Habashneh R, Khader Y, Hammad MM, Almuradi M. Knowledge and awareness about diabetes and periodontal health among Jordanians. J Diabetes Complications. 2010;24(6):409-414. 
14. Strauss SM, Singh G, Tuthill J, Brodsky A, Rosedale M, Bytyci A, et al. Diabetesrelated knowledge and sources of information among periodontal patients: Is there a role for dental hygienists. Journal of Dental Hygiene. 2013;87(2):82-89.

15. Bahammam MA. Periodontal health and diabetes awareness among Saudi diabetes. Dovepress. 2015;9:225-233.

16. Awartin F. Oral health knowledge and practices in Saudi diabetic female patients. Pakistan Oral \& Dental Journal. 2009;29(1):149-152.

17. Aggarwal A, Panat $S$. Oral health behaviour and $\mathrm{HbA} 1 \mathrm{c}$ in Indian adults with type 2 diabetes. Journal of Oral Science. 2012;54(4):293-301.

18. Karikoski A, llanne-Parikka $P$, Murtomaa $H$. Oral self-care among adults with diabetes in Finland. Community Dent Oral Epidemiol. 2002;30:216-223.

19. Murtomaa $\mathrm{H}$, Metsaniitty $\mathrm{M}$. Trends in tooth brushing and utilization of dental services in Finland. Community Dent Oral Epiodemiol. 1994;22:231-234.

20. Allen EM, Ziada HM, O'Halloran D, Clerehugh V, Allen PF. Attitude, awareness and oral health- related quality of life in patients with diabetes. J Oral Rehabil. 2008;35(3):218-23. 


\section{QUESTIONNAIRE}

Diabetic Patients Knowledge and Attitude towards the Oral Complications of Diabetes Mellitus and Factors Associated with Their Knowledge in Khartoum State, Sudan

This research questionnaire is designed for scientific purposes and to change towards the best:

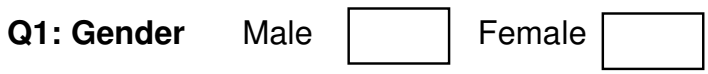

Q2: Age

Years old

Q3: Residence Khartoum state Outside Khartoum state

Q4: If lived in Khartoum State, for how long?

Less than 5 years Between 5-10 years

More than 10 years

Q5: Level of education

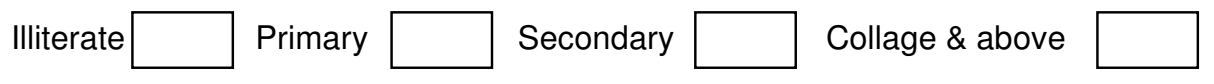

Q6: Which type of diabetes mellitus do you have?

Type 1

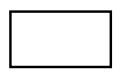

Type 2

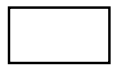

I don't know

Q7: How long has it been since you have been diagnosed with Diabetes mellitus?

Less than 1 year

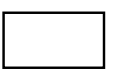

1-5 years

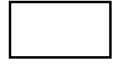

6-10 years

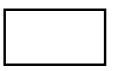

More than 10 years

Q8: Do you visit your physician regularly regarding your diabetes mellitus disease?

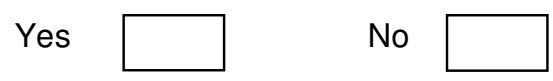

Q9: Did you visit the physician during the last year?

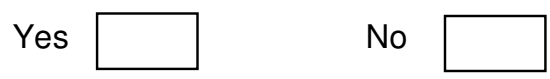

Q10: Do you visit the Dentist regularly?

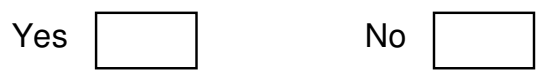

Q11: Did you visit the dentist during the last year?

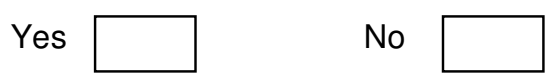


Q12: If yes, what was the reason behind your visit to the dentist?

Toothache $\square$ gum inflammation $\square$ tooth Movement $\square$ Check-up $\square$

Q13: Do you brush your teeth?

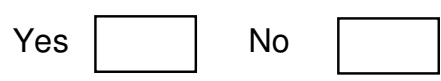

Q14: If yes, how often do you brush your teeth during the day?

Once a day $\square$ Twice a day $\square$ More than twice $\square$

Q15: If you have an oral problem, what will you do?

Consult physician $\square$ Consult Dentist $\square$ Self Remedy $\square$ Ignore it $\square$

Q16:

\begin{tabular}{|c|c|c|c|c|c|}
\hline Questions & $\begin{array}{l}\text { Strongly } \\
\text { agree }\end{array}$ & Agree & $\begin{array}{l}\text { Strongly } \\
\text { disagree }\end{array}$ & Disagree & $\begin{array}{l}\text { Don't } \\
\text { know }\end{array}$ \\
\hline \multicolumn{6}{|l|}{$\begin{array}{l}\text { Diabetes mellitus has an effect on your oral } \\
\text { cavity health }\end{array}$} \\
\hline \multicolumn{6}{|l|}{$\begin{array}{l}\text { Diabetes mellitus complications in the mouth } \\
\text { can affect your glycemic control status }\end{array}$} \\
\hline \multicolumn{6}{|l|}{$\begin{array}{l}\text { Diabetes mellitus can affects your gum health } \\
\text { and may end in teeth loss }\end{array}$} \\
\hline \multicolumn{6}{|l|}{$\begin{array}{l}\text { Diabetic patients are more prone to dental } \\
\text { caries }\end{array}$} \\
\hline \multicolumn{6}{|l|}{$\begin{array}{l}\text { Diabetic patients are more prone to oral fungal } \\
\text { infections }\end{array}$} \\
\hline \multicolumn{6}{|l|}{$\begin{array}{l}\text { Bleeding during brushing is a sign of gum } \\
\text { diseases }\end{array}$} \\
\hline \multicolumn{6}{|l|}{$\begin{array}{l}\text { Diabetes mellitus has effects on the heart } \\
\text { health }\end{array}$} \\
\hline \multicolumn{6}{|l|}{$\begin{array}{l}\text { Diabetes mellitus has effects on the kidneys } \\
\text { health }\end{array}$} \\
\hline \multicolumn{6}{|l|}{$\begin{array}{l}\text { Diabetes mellitus has effects on the eyes } \\
\text { health }\end{array}$} \\
\hline \multicolumn{6}{|l|}{ Diabetes mellitus affects the nerves } \\
\hline $\begin{array}{l}\text { Diabetic foot is a complication of Diabetes } \\
\text { mellitus }\end{array}$ & & & & & \\
\hline
\end{tabular}

Q17: What is your source of information regarding Diabetes mellitus Oral complications?

Physician $\square$ Dentist $\square$ Media $\square$ Family\& relatives $\square$ None $\square$ 
Q18: Did you receive any advice from your dentist regarding diabetes mellitus oral complications
Yes
No

Q19: Do you think it is necessary to get education regarding diabetes mellitus oral complications

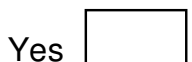

No

Thank you for your cooperation

(C) 2017 Elsayed and Awooda; This is an Open Access article distributed under the terms of the Creative Commons Attribution License (http://creativecommons.org/licenses/by/4.0), which permits unrestricted use, distribution, and reproduction in any medium, provided the original work is properly cited.

Peer-review history:

The peer review history for this paper can be accessed here:

http://sciencedomain.org/review-history/18986 